Scientific Journal of Silesian University of Technology. Series Transport Zeszyty Naukowe Politechniki Śląskiej. Seria Transport

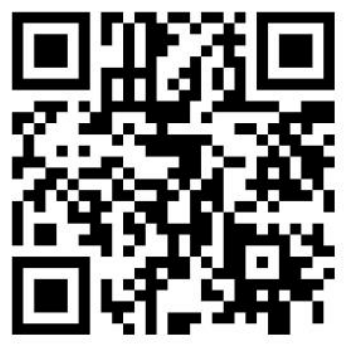

Volume 112

2021

p-ISSN: 0209-3324

e-ISSN: 2450-1549

DOI: https://doi.org/10.20858/sjsutst.2021.112.1

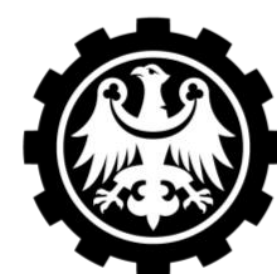

Silesian

University of Technology

Journal homepage: http://sjsutst.polsl.pl

Article citation information:

Akgüngör, A.P., Mercan, E.Z. An analysis of Type I dilemma zone at signalised intersections. Scientific Journal of Silesian University of Technology. Series Transport. 2021, 112, 05-16. ISSN: 0209-3324. DOI: https://doi.org/10.20858/sjsutst.2021.112.1.

\author{
Ali Payıdar AKGÜNGÖR ${ }^{1}$, Elif Zahide MERCAN²
}

\title{
AN ANALYSIS OF TYPE I DILEMMA ZONE AT SIGNALISED INTERSECTIONS
}

Summary. Intersections, for vehicles coming from different directions, are conflict points in road networks. When a driver approaching a signalised intersection encounters the yellow light, he/she is in a dilemma either to safely stop or to pass through the intersection during clearance time. The decision to stop or to pass may change depending on some factors such as duration of yellow light, deceleration and acceleration rate, width of intersection, speed and length of vehicle, etc. This study aims to put forth the effects of some related factors affecting the length of the Type I dilemma zone. To perform this study, five factors including vehicle speed, maximum deceleration rate, perception-reaction time, clearance time, the total intersection width-vehicle length were considered and a total of 648 different traffic cases were investigated. The study results showed that the Type I dilemma zone length increased with the increase of speed, total intersection widthvehicle length and perception-reaction time, but decreased with the increase of clearance time and deceleration rate.

Keywords: dilemma zone, signalised intersections, stop or go decision

\footnotetext{
${ }^{1}$ Kırıkkale University, Faculty of Engineering, Department of Civil Engineering, Transportation Division, 71451 Yahşihan/Kırıkkale, Turkey. Email:aakgungor@gmail.com. ORCID: https://orcid.org/0000-0003-0669-5715

${ }^{2}$ Kirıkkale University, Faculty of Engineering, Department of Civil Engineering, Transportation Division, 71451 Yahşihan/Kırıkkale, Turkey. Email:elifmercan03@gmail.com. ORCID: https://orcid.org/0000-0003-2898-5684
} 


\section{INTRODUCTION}

Intersections are potential accident areas in road networks because two or more traffic streams cross or merge on the approach. To provide a safety manoeuvre movement for both vehicles and pedestrian traffic at the intersection, they are signalised with optimum signal time based on time-sharing principles. Although traffic signalisation mostly prevents traffic accidents at intersections, collisions occur for various reasons such as driver behaviours, speed, the duration of perception-reaction time and yellow time. As drivers approach a signalised intersection, when the traffic signal changes from green to yellow, travelling vehicles stay in a zone where they have to decide to stop or go at the intersection to prevent a potential rightangle collision or rear-end collision. Gazis et al. first introduced this safety problem at signalised intersections to traffic engineering literature as a dilemma zone problem. They defined the dilemma zone $(D Z)$ as a zone that vehicles at the onset of the yellow indication neither stop safely nor pass clearly through the intersection before the stop line [9]. This concept as proposed by Gazis et al. is also known as the Type I dilemma zone [17, 29, 30]. The reason for the Type I dilemma zone is associated with inappropriate signal timing. Especially, insufficient yellow or clearance time (yellow time + all red time) causes the Type I dilemma zone. On the other hand, it has been recognised that longer yellow or clearance intervals could eliminate the Type I dilemma zone; however, it would lead to longer option zones where drivers are indecisive to stop or cross at the onset of yellow light. This option zone is called the Type II dilemma zone or "Indecision zone" [15]. The Type II dilemma zone was formally proposed by the Southern Section of ITE and included in the technical committee report in 1974 [12]. Several studies have been conducted to define the location of the Type II dilemma zone based on the possibility of stopping [3, 20, 31, 32]. Zegeer and Deen suggested an approach to defining the boundaries of the Type II dilemma zone depending on the driver's decisionmaking. They expressed the dilemma zone as a zone where more than $10 \%$ and less than $90 \%$ of drivers would choose to stop at the start of the yellow signal [32].

The Type I and Type II dilemma zones are depicted in Figure 1. Here, $X_{C}$ is the minimum distance from the stop line where a vehicle can safely stop before the stop line, and $X_{0}$ is the maximum distance from the stop line where a vehicle can cross and clear the intersection by the end of the clearance time. In their study, Gazis et al. derived the values of $X_{C}$ and $X_{0}$ given in Equations 1 and 2 [9].

$$
\begin{aligned}
& X_{C}=V_{0} \cdot t_{r}+\frac{V_{0}^{2}}{2 d_{\max }} \\
& X_{0}=V_{0} \tau-(W+L)+\frac{1}{2} a_{\max }\left(\tau-t_{r}\right)^{2}
\end{aligned}
$$

where:

$X_{C}$ is minimum stopping distance $(\mathrm{m}), V_{O}$ is vehicle speed onsetting yellow time $(\mathrm{m} / \mathrm{s}), t_{r}$ is driver's perception- reaction time (sec), $d_{\text {max }}$ is maximum deceleration rate of vehicle $\left(\mathrm{m} / \mathrm{s}^{2}\right)$, $X_{0}$ is the maximum safety crossing distance $(\mathrm{m}), \tau$ is yellow time $(\mathrm{sec}), W$ is the intersection width $(\mathrm{m}), L$ is average vehicle length $(\mathrm{m}), a_{\max }$ is the maximum acceleration rate of vehicle $\left(\mathrm{m} / \mathrm{s}^{2}\right)$.

If a driver keeps his vehicle speed without accelerating while approaching the intersection when he encounters the yellow light, Equation 3 can be expressed as follows. 


$$
\begin{gathered}
X_{0}=V_{0} t_{C}-(W+L) \\
t_{C}=t_{y}+t_{\text {All Red }}
\end{gathered}
$$

where:

$t_{C}$ is clearance time (sec) consisting of the sum of yellow time and all red time, $t_{y}$ is yellow time and $t_{A l l \text { Red }}$ is safety interval for all directions.

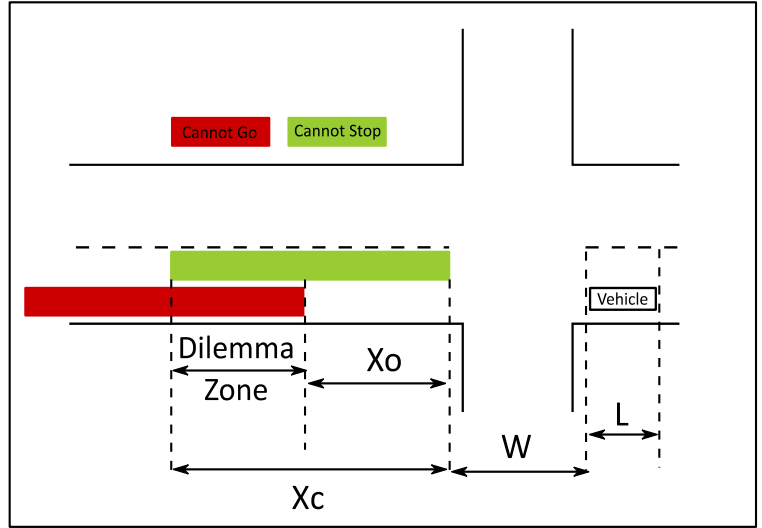

(a)

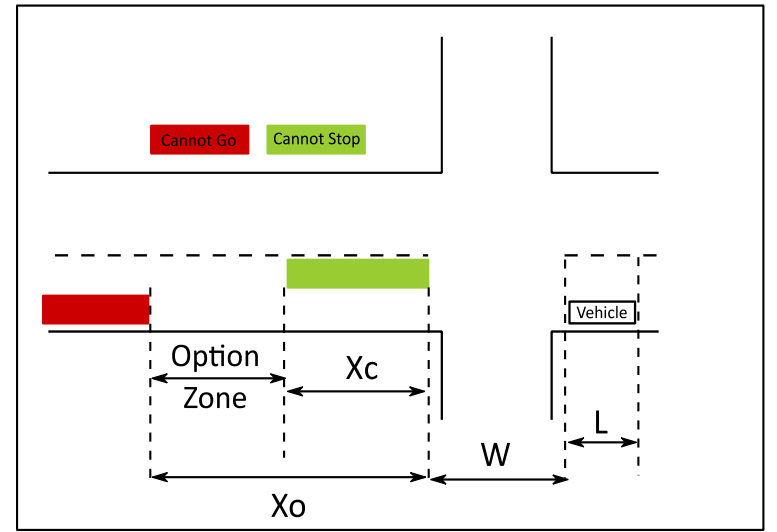

(b)

Fig. 1. a. The Type I dilemma zone b. Type II dilemma (option) zone

As seen from Figure 1, when $X_{C}$ is greater than $X_{0}$, the vehicle physically locates somewhere between $X_{C}$ and $X_{0}$ and the Type 1 dilemma zone exists. On the other hand, when $X_{0}$ is greater than $X c$, then as the clearance time passing distance is greater than the minimum stopping distance, the vehicle is within an option zone. It means the driver can either stop safely or proceed through the intersection before the end of clearance time. Regardless of the decision, the driver can make it.

Different factors, such as vehicle speed, distance to intersection, the size of vehicle, driver's perception-reaction time, the length of yellow time, etc., affect the driver behaviour and the length of the dilemma zones. Besides, the existence of the dilemma zone is also effective on the performance and safety of the intersection. Therefore, the analysis of the factors that could affect the dilemma zone has been one important issue of traffic engineering.

\section{INFLUENCING FACTORS TO DILEMMA ZONE LENGTHS}

Traffic is a dynamic process in nature, thus, many factors affect drivers' behaviour. Each driver approaching a signalised intersection may react differently on seeing the yellow signal. Given decisions may change based on driver behaviours, traffic flow conditions, intersection and vehicle characteristics $[2,4,5,21]$. Among them, driver behaviour plays an important role in the drivers' decision-making process and intersection safety [11, 19, 24].

Some drivers are aggressive and prone to accidents while others are calm, obeying the rules. Two parameters, such as perception-reaction time and acceleration/deceleration rate, affect the driving performance of most drivers. Many studies have investigated the effects of these two parameters on traffic flow [6-8, 10, 16, 26, 28]. However, the parameters of the Type I dilemma zone like perception-reaction time and acceleration/deceleration rate are assumed constant value. ITE recommended $3.05 \mathrm{~m} / \mathrm{s}^{2}, 0 \mathrm{~m} / \mathrm{s}^{2}$ and $1.0 \mathrm{sec}$, respectively, for deceleration, 
acceleration and perception-reaction time values [13]. The design standards of the American Association of State Highway and Transportation Officials (AASHTO) also defined $3.41 \mathrm{~m} / \mathrm{s}^{2}$, $0 \mathrm{~m} / \mathrm{s}^{2}$ and $1.5 \mathrm{sec}$, respectively, as the default value of deceleration, acceleration and perception time [1]. Although Gazis et al., considered acceleration rate as a linear function of speed, acceleration rate in most studies generally was assumed constant as $0 \mathrm{~m} / \mathrm{s}^{2}$. Saito et al. investigated the relation between deceleration rate and stopped vehicles. The study result indicated that the range for deceleration rate was between 1.5 and $6 \mathrm{~m} / \mathrm{s}^{2}$. The average value of $3.6 \mathrm{~m} / \mathrm{s}^{2}$ was in 50 percentile value. In the same study, the average reaction time for stopping ranged approximately 1-2 sec. Rakha et al. (2007) performed a field study to determine the average perception-reaction time and expressed that observed samples ranged from 0.3 to $1.7 \mathrm{sec}$.

Vehicle speed, distance from stop line, the length of intersection, duration of yellow and clearance time are other parameters that affect driver decisions in the dilemma zones. Hence, the length and type of dilemma zones can be varied based on decisions by the drivers [25]. However, the studies by Urbanik and Koonce, and Si et al. showed that the Type I dilemma zone is eliminated by adequate yellow and clearance times [27,30]. Saito et al. obtained similar results related to the Type I dilemma zone with their observation study before Urbanik and Koone's study [25]. According to the study results, as yellow and clearance times increased, vehicle rate in the Type I dilemma zone decreased but increased in the option zone. Rakha et al. stated that when the yellow light is turned on, in the case that a vehicle travelled at high speed and it was a close distance to the stop line, the stopping probability of that vehicle at the intersection was low. They also pointed out that most drivers would not stop at the intersection if the time to the intersection is $1.6 \mathrm{~s}$ at the beginning of the yellow interval [23]. Puan and Ismail posited that most drivers were reluctant to stop at the onset of the yellow time. On the other hand, they expressed that most drivers tend to stop at the beginning of the yellow interval, if travelling at low speed, approaching a large and sophisticated intersection, having a long distance to stop line, and driving in heavy traffic [22].

Besides the above factors, other potential factors such as vehicle type, adverse weather, driver experience, gradient, pavement conditions, position in a platoon, signal control type, pedestrian behaviours, existence of countdowns can affect driver behaviour in a dilemma zone $[19,33]$.

\section{ANALYTIC STUDY OF THE DILEMMA ZONE FOR SIGNALISED INTERSECTIONS}

The control of an intersection for safe crossing can be provided by the signalisation system. However, the deficiency of signalisation at high-speed signalised intersections where the speed limit is greater than $65 \mathrm{~km} / \mathrm{h}$ dilemma zone may cause problems, which may result in rear-end and right-angle crashes. As explained above, several factors affect the length and type of dilemma zone. Subsequently, an analytical study was conducted employing Equations 1 and 3 to find out the effectiveness of the influencing factors on the dilemma zone. In the study, vehicle speeds $V_{O}$ were changed from $50 \mathrm{~km} / \mathrm{h}(13.89 \mathrm{~m} / \mathrm{s})$ to $100 \mathrm{~km} / \mathrm{h}(27.78 \mathrm{~m} / \mathrm{s})$ with $10 \mathrm{~km} / \mathrm{h}$ $(2.78 \mathrm{~m} / \mathrm{s})$ increments while the clearance times of the intersection were varied from 3 to 6 seconds. Selected clearance times for this study are plausible, as the Manual on Uniform Traffic Control Devices recommends that the minimum and maximum yellow time are 3 and 6 seconds, respectively [18]. In addition, the Manual of Traffic Signal Design emphasises that a clearance time greater than 6 seconds be carefully examined before being implemented [14]. 
Human perception-reaction time varies between 0.8 and 2.5 seconds depending on age, sex, visibility, concentration and the environmental conditions at the time of response. While this period increases with alcohol use and fatigue, it can decrease with experience and focused attention. For signal timing purposes, the ITE recommends a perception-reaction time of 1.0 second for simplicity [13]. AASHTO allows 1.5 seconds for perception time and 1.0 second for reaction time [1]. Some studies suggest that the upper range of perception-reaction time begins at 0.78 second in the laboratory environment and become 2.50 seconds in an urban street in real-time. Therefore, the driver's perception-reaction time $t_{r}$ ranges from 1 to 2 seconds with $0.5 \mathrm{sec}$. increments in this study.

The maximum deceleration rate of vehicle $d_{\text {max }}$ is an important factor in determining the boundaries of dilemma zones, and varies from vehicle to vehicle, depending on vehicle speeds and characteristics. The value of maximum deceleration rate is assumed to be constant as $3.41 \mathrm{~m} / \mathrm{s}^{2}\left(11.2 \mathrm{ft} / \mathrm{s}^{2}\right)$ by AASHTO and $3.05 \mathrm{~m} / \mathrm{s}^{2}\left(10 \mathrm{ft} / \mathrm{s}^{2}\right)$ by the ITE $(1,9)$. Therefore, maximum deceleration rate of vehicle is assumed $2,3,4 \mathrm{~m} / \mathrm{s}^{2}$ in this work.

When a driver approaching a signalised intersection encounters the yellow light within the dilemma zone, his or her decision of passing or not passing the intersection may vary depending on his or her vehicle speed, the size of the intersection, distance to the stop line and the length of the vehicle he or she uses. Drivers usually tend to stop at the beginning of the yellow light at complex intersections consisting of 3 or more lanes while they tend to proceed during clearance interval at the smaller intersections. In analysing the dilemma zone, both small and large intersection considered the effect of intersections, the sum of intersection width $W$ and the average vehicle length $L$ as 15,25 and $35 \mathrm{~m}$, respectively.

In the analysis of the dilemma zone, a total of $6 \times 4 \times 3 \times 3 \times 3=648$ different traffic cases were considered and their interaction among them was investigated. The parameters and their values examined are given in Table 1.

Tab. 1

Effective parameters used in the dilemma zone calculations and their values

\begin{tabular}{ccccc}
\hline $\begin{array}{c}\text { Speed }\left(V_{0}\right) \\
(\mathrm{km} / \mathrm{h}) /(\mathrm{m} / \mathrm{s})\end{array}$ & $\begin{array}{c}\text { Clearance } \\
\text { time } t_{c}(\mathrm{~s})\end{array}$ & $\begin{array}{c}\text { Maximum } \\
\text { deceleration rate } \\
d_{\max } \\
\left(\mathrm{m} / \mathrm{s}^{2}\right)\end{array}$ & $\begin{array}{c}\text { Perception- } \\
\text { reaction time } \\
t_{r} \\
(\mathrm{~s})\end{array}$ & $\begin{array}{c}\text { Total length of } \\
\text { intersection and } \\
\text { vehicle } W \\
(\mathrm{~m})\end{array}$ \\
\hline $50 / 13.89$ & 3 & 2 & 1 & 15 \\
$60 / 16.67$ & 4 & 3 & 1.5 & 25 \\
$70 / 19.45$ & 5 & 4 & 2 & 35 \\
$80 / 22.22$ & 6 & & & \\
$90 / 25.00$ & & & & \\
$100 / 27.78$ & & & & \\
\hline
\end{tabular}

Dilemma and option zones for 648 various traffic cases were calculated using Equations 1 and 3. Tables 2 and 3 show the relationship among various speed, clearance time and the intersection width plus vehicle length on dilemma zones for the same deceleration rate and perception-reaction time $\left(a=3 \mathrm{~m} / \mathrm{s}^{2}\right.$ and $\left.t_{r}=1.5 \mathrm{~s}\right)$. 
The relation between speed and clearance time with $W=15 \mathrm{~m}$ for the dilemma zone $\left(a=3 \mathrm{~m} / \mathrm{s}^{2}\right.$ and $\left.t_{r}=1.5 \mathrm{~s}\right)$

\begin{tabular}{ccccccccccccccc}
\hline & \multicolumn{3}{c}{$\boldsymbol{t} \boldsymbol{c}=\mathbf{3} \mathbf{~ s}$} & \multicolumn{4}{c}{$\boldsymbol{t} \boldsymbol{c}=\mathbf{4} \mathbf{~ s}$} & \multicolumn{3}{c}{$\boldsymbol{t} \boldsymbol{c}=\mathbf{5} \mathbf{s}$} & \multicolumn{3}{c}{$\boldsymbol{t} \boldsymbol{c}=\mathbf{6} \mathbf{~ s}$} \\
\cline { 2 - 14 } $\begin{array}{c}\text { Speed } \\
(\mathbf{k m} / \mathbf{h})\end{array}$ & $X_{s}(\mathrm{~m})$ & $\begin{array}{c}X_{0} \\
(\mathrm{~m})\end{array}$ & $\begin{array}{c}D Z \\
(\mathrm{~m})\end{array}$ & $X_{s}(\mathrm{~m})$ & $\begin{array}{c}X_{0} \\
(\mathrm{~m})\end{array}$ & $\begin{array}{c}D Z \\
(\mathrm{~m})\end{array}$ & $X_{s}(\mathrm{~m})$ & $X_{0}(\mathrm{~m})$ & $\begin{array}{c}D Z \\
(\mathrm{~m})\end{array}$ & $X_{s}(\mathrm{~m})$ & $X_{0}(\mathrm{~m})$ & $D Z(\mathrm{~m})$ \\
\hline 50 & 52.99 & 26.67 & 26.32 & 52.99 & 40.56 & 12.43 & 52.99 & 54.45 & -1.46 & 52.99 & 68.34 & -15.35 \\
60 & 71.31 & 35.00 & 36.30 & 71.31 & 51.67 & 19.63 & 71.31 & 68.34 & 2.97 & 71.31 & 85.01 & -13.70 \\
70 & 92.19 & 43.34 & 48.86 & 92.19 & 62.78 & 29.41 & 92.19 & 82.23 & 9.96 & 92.19 & 101.68 & -9.48 \\
80 & 115.65 & 51.67 & 63.98 & 115.65 & 73.90 & 41.76 & 115.65 & 96.12 & 19.53 & 115.65 & 118.34 & -2.69 \\
90 & 141.69 & 60.01 & 81.68 & 141.69 & 85.01 & 56.68 & 141.69 & 110.01 & 31.68 & 141.69 & 135.01 & 6.67 \\
100 & 170.29 & 68.34 & 101.95 & 170.29 & 96.12 & 74.17 & 170.29 & 123.90 & 46.39 & 170.29 & 151.68 & 18.61 \\
\hline
\end{tabular}

Tab. 3

The relation between speed and clearance time with $W=35 \mathrm{~m}$ for the dilemma zone $\left(a=3 \mathrm{~m} / \mathrm{s}^{2}\right.$ and $\left.t r=1.5 \mathrm{~s}\right)$

\begin{tabular}{cccccccccccccc}
\hline & \multicolumn{3}{c}{$\boldsymbol{t} \boldsymbol{c}=\mathbf{3 ~ s}$} & \multicolumn{3}{c}{$\boldsymbol{t} \boldsymbol{c}=\mathbf{4} \mathbf{~ s}$} & \multicolumn{3}{c}{$\boldsymbol{t} \boldsymbol{c}=\mathbf{5} \mathbf{s}$} & \multicolumn{3}{c}{$\boldsymbol{t} \boldsymbol{c}=\mathbf{6} \mathbf{~ s}$} \\
\cline { 2 - 13 } $\begin{array}{c}\text { Speed } \\
(\mathbf{k m} / \mathbf{h})\end{array}$ & $X_{s}(\mathrm{~m})$ & $\begin{array}{c}X_{0} \\
(\mathrm{~m})\end{array}$ & $\begin{array}{c}D Z \\
(\mathrm{~m})\end{array}$ & $X_{s}(\mathrm{~m})$ & $\begin{array}{c}X_{0} \\
(\mathrm{~m})\end{array}$ & $\begin{array}{c}D Z \\
(\mathrm{~m})\end{array}$ & $X_{s}(\mathrm{~m})$ & $X_{0}(\mathrm{~m})$ & $\begin{array}{c}D Z \\
(\mathrm{~m})\end{array}$ & $X_{s}(\mathrm{~m})$ & $X_{0}(\mathrm{~m})$ & $\begin{array}{c}D Z \\
(\mathrm{~m})\end{array}$ \\
\hline 50 & 52.99 & 6.67 & 46.32 & 52.99 & 20.56 & 32.43 & 52.99 & 34.45 & 18.54 & 52.99 & 48.34 & 4.65 \\
60 & 71.31 & 15.00 & 56.30 & 71.31 & 31.67 & 39.63 & 71.31 & 48.34 & 22.97 & 71.31 & 65.01 & 6.30 \\
70 & 92.19 & 23.34 & 68.86 & 92.19 & 42.78 & 49.41 & 92.19 & 62.23 & 29.96 & 92.19 & 81.68 & 10.52 \\
80 & 115.65 & 31.67 & 83.98 & 115.65 & 53.90 & 61.76 & 115.65 & 76.12 & 39.53 & 115.65 & 98.34 & 17.31 \\
90 & 141.69 & 40.01 & 101.68 & 141.69 & 65.01 & 76.68 & 141.69 & 90.01 & 51.68 & 141.69 & 115.01 & 26.67 \\
100 & 170.29 & 48.34 & 121.95 & 170.29 & 76.12 & 94.17 & 170.29 & 103.90 & 66.39 & 170.29 & 131.68 & 38.61 \\
\hline
\end{tabular}

As seen from the Tables above, it is realised that the Type I dilemma zone length increases with the increase of speed but decreases with the increase of clearance time. Additionally, an increase in clearance time causes the Type 1 dilemma zone to disappear while the dilemma zone of Type 2, known as the stop or go decision zone, arises (Table 2). At the same time, an increase in the width of the intersection also causes an increment in the length of the Type I dilemma zone (Figure 3).

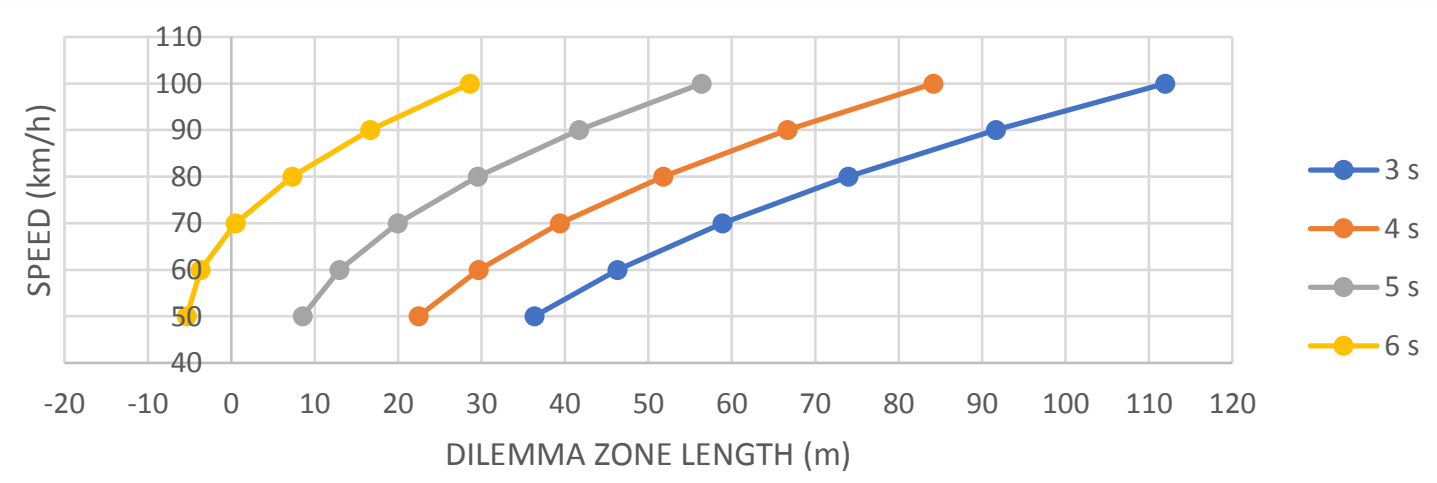

Fig. 2. The relation between speed and clearance time with $W=25 \mathrm{~m}$ for the dilemma zone $\left(a=3 \mathrm{~m} / \mathrm{s}^{2}\right.$ and $\left.t r=1.5 \mathrm{~s}\right)$ 


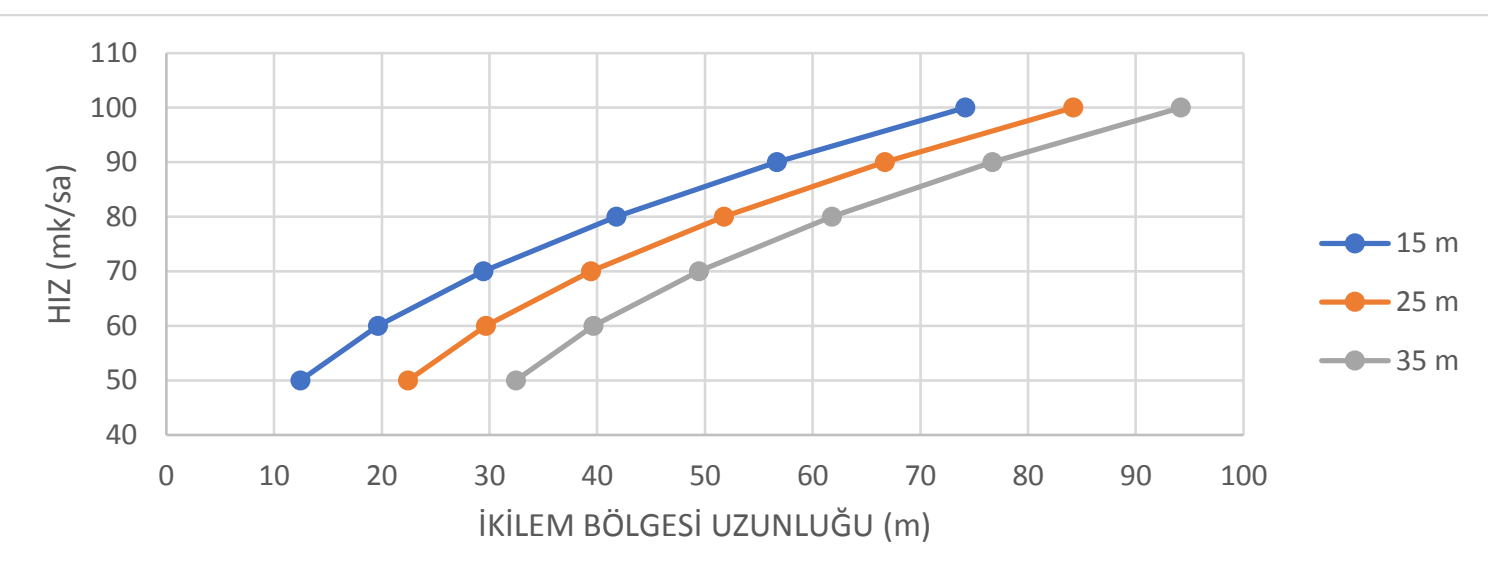

Fig. 3. The relation between speed and intersection width and dilemma zone length

$$
\left(t_{c}=4, a=3 \mathrm{~m} / \mathrm{s}^{2} \text { and } t r=1.5 \mathrm{~s}\right)
$$

Tab. 4

The relation between speed and deceleration rate with $t_{r}=1 \mathrm{sec}$ for the dilemma zone

$$
\left(t_{c}=3 \mathrm{~s}, W=25 \mathrm{~m}\right)
$$

\begin{tabular}{|c|c|c|c|c|c|c|c|c|c|}
\hline \multirow[b]{2}{*}{$\begin{array}{l}\text { Speed } \\
(\mathbf{k m} / \mathbf{h})\end{array}$} & \multicolumn{3}{|c|}{$a=2 \mathrm{~m} / \mathrm{s}^{2}$} & \multicolumn{3}{|c|}{$a=3 \mathrm{~m} / \mathrm{s}^{2}$} & \multicolumn{3}{|c|}{$a=4 \mathrm{~m} / \mathrm{s}^{2}$} \\
\hline & $X_{s}(\mathrm{~m})$ & $X_{0}(\mathrm{~m})$ & $D Z(\mathrm{~m})$ & $X_{S}(\mathrm{~m})$ & $X_{0}(\mathrm{~m})$ & $D Z(\mathrm{~m})$ & $X_{s}(\mathrm{~m})$ & $\begin{array}{c}X_{0} \\
(\mathrm{~m}) \\
\end{array}$ & $\begin{array}{l}D Z \\
(\mathrm{~m}) \\
\end{array}$ \\
\hline 50 & 62.12 & 16.67 & 45.45 & 46.05 & 16.67 & 29.38 & 38.01 & 16.67 & 21.34 \\
\hline 60 & 86.12 & 25.00 & 61.12 & 62.97 & 25.00 & 37.97 & 51.40 & 25.00 & 26.39 \\
\hline 70 & 113.98 & 33.34 & 80.64 & 82.47 & 33.34 & 49.13 & 66.71 & 33.34 & 33.38 \\
\hline 80 & 145.70 & 41.67 & 104.03 & 104.54 & 41.67 & 62.87 & 83.96 & 41.67 & 42.29 \\
\hline 90 & 181.28 & 50.01 & 131.27 & 129.19 & 50.01 & 79.18 & 103.14 & 50.01 & 53.13 \\
\hline 100 & 220.71 & 58.34 & 162.37 & 156.40 & 58.34 & 98.06 & 124.25 & 58.34 & 65.91 \\
\hline
\end{tabular}

Tab 5.

The relation between speed and deceleration rate with $t_{r}=2 \mathrm{~s}$ for the dilemma zone

$$
\left(t_{c}=3 \mathrm{~s}, W=25 \mathrm{~m}\right)
$$

\begin{tabular}{ccccccccccc}
\hline & \multicolumn{3}{c}{$\boldsymbol{a}=\mathbf{2} \mathbf{~ m} / \mathbf{s}^{\mathbf{2}}$} & \multicolumn{3}{c}{$\boldsymbol{a}=\mathbf{3} \mathbf{~ m} / \mathbf{s}^{\mathbf{2}}$} & \multicolumn{3}{c}{$\boldsymbol{a}=\mathbf{4} \mathbf{~ m} / \mathbf{s}^{\mathbf{2}}$} \\
\cline { 2 - 11 } $\begin{array}{c}\text { Speed } \\
(\mathbf{k m} / \mathbf{h})\end{array}$ & $X_{s}(\mathrm{~m})$ & $X_{0}(\mathrm{~m})$ & $D Z(\mathrm{~m})$ & $X_{s}(\mathrm{~m})$ & $X_{0}(\mathrm{~m})$ & $D Z(\mathrm{~m})$ & $X_{S}(\mathrm{~m})$ & $\begin{array}{c}X_{0} \\
(\mathrm{~m})\end{array}$ & $\begin{array}{c}D Z \\
(\mathrm{~m})\end{array}$ \\
\hline 50 & 76.01 & 16.67 & 59.34 & 59.94 & 16.67 & 43.27 & 51.90 & 16.67 & 35.23 \\
60 & 102.79 & 25.00 & 77.79 & 79.64 & 25.00 & 54.64 & 68.06 & 25.00 & 43.06 \\
70 & 133.43 & 33.34 & 100.09 & 101.92 & 33.34 & 68.58 & 86.16 & 33.34 & 52.82 \\
80 & 167.92 & 41.67 & 126.25 & 126.77 & 41.67 & 85.09 & 106.19 & 41.67 & 64.51 \\
90 & 206.28 & 50.01 & 156.27 & 154.19 & 50.01 & 104.18 & 128.14 & 50.01 & 78.14 \\
100 & 248.49 & 58.34 & 190.15 & 184.18 & 58.34 & 125.84 & 152.03 & 58.34 & 93.69 \\
\hline
\end{tabular}




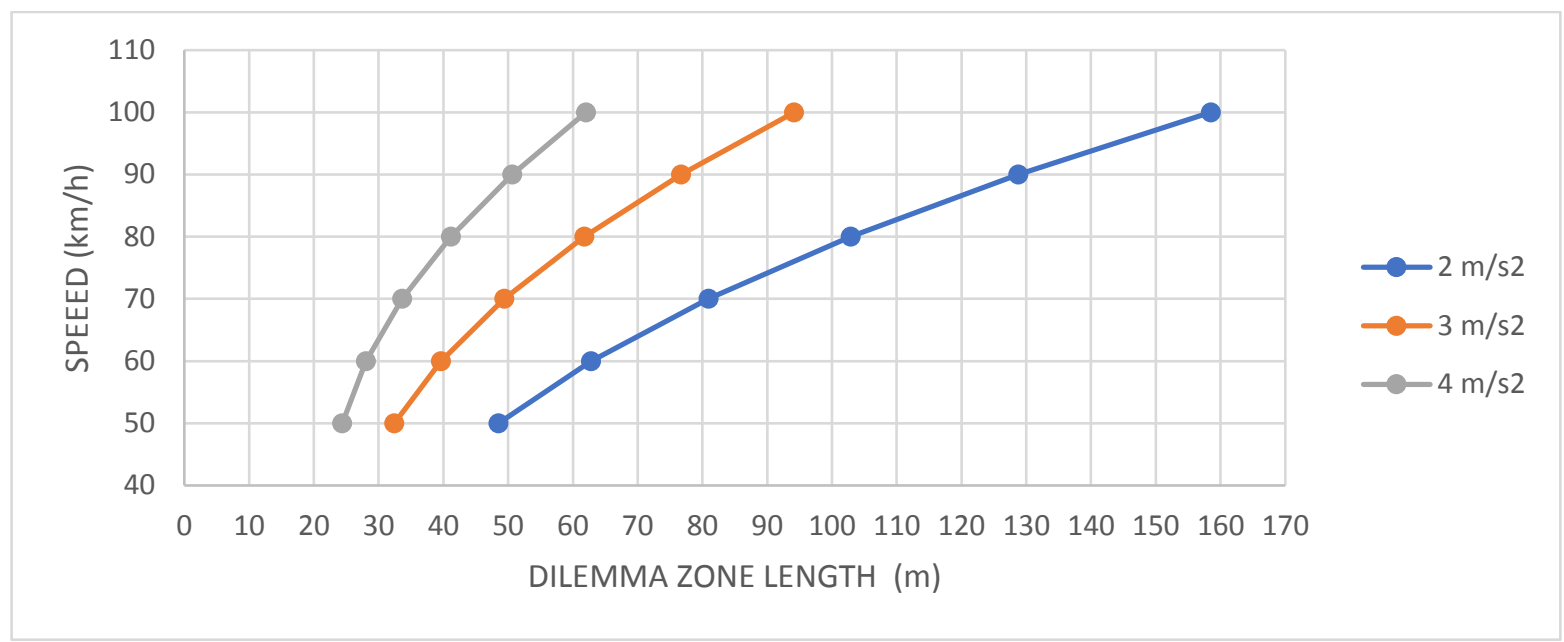

Fig. 4. The relation between speed, deceleration rate and the dilemma zone

$$
\left(t_{c}=4 \mathrm{~s}, t_{r}=2 \mathrm{~s}, W=35 \mathrm{~m}\right)
$$

It is noted that the Type I dilemma zone length enlarges with the increase of speed yet decreases with the increase of deceleration rate, as shown in Figure 4, Tables 4 and 5. Moreover, an increase in perception-reaction time leads to an increase in the length of the Type 1 dilemma zone under the same intersection width and clearance time.

Tab. 6

The relation between clearance time and perception-reaction time with $V_{0}=60 \mathrm{~km} / \mathrm{h}$ for the dilemma zone $\left(a=3 \mathrm{~m} / \mathrm{s}^{2}, W=35 \mathrm{~m}\right)$

\begin{tabular}{ccccccccccc}
\hline & \multicolumn{3}{c}{$\boldsymbol{t r}=\mathbf{1 ~ s}$} & \multicolumn{3}{c}{$\boldsymbol{t r}=\mathbf{1 . 5} \mathbf{s}$} & \multicolumn{3}{c}{$\boldsymbol{t r}=\mathbf{2} \mathbf{~ s}$} \\
\cline { 2 - 11 } $\begin{array}{c}\text { Clearance Time } \\
(\mathbf{s})\end{array}$ & $X_{s}(\mathrm{~m})$ & $X_{0}(\mathrm{~m})$ & $D Z(\mathrm{~m})$ & $X_{s}(\mathrm{~m})$ & $\begin{array}{c}X_{0} \\
(\mathrm{~m})\end{array}$ & $D Z(\mathrm{~m})$ & $X_{s}(\mathrm{~m})$ & $\begin{array}{c}X_{0} \\
(\mathrm{~m})\end{array}$ & $\begin{array}{c}D Z \\
(\mathrm{~m})\end{array}$ \\
\hline 3 & 62.97 & 15.00 & 47.97 & 71.31 & 15.00 & 56.30 & 79.64 & 15.00 & 64.64 \\
4 & 62.97 & 31.67 & 31.30 & 71.31 & 31.67 & 39.63 & 79.64 & 31.67 & 47.97 \\
5 & 62.97 & 48.34 & 14.63 & 71.31 & 48.34 & 22.97 & 79.64 & 48.34 & 31.30 \\
6 & 62.97 & 65.01 & -2.04 & 71.31 & 65.01 & 6.30 & 79.64 & 65.01 & 14.63 \\
\hline
\end{tabular}

Tab. 7

The relation between clearance time and perception-reaction time with $V_{0}=90 \mathrm{~km} / \mathrm{h}$ for the dilemma zone $\left(a=3 \mathrm{~m} / \mathrm{s}^{2}, W=35 \mathrm{~m}\right)$

\begin{tabular}{ccccccccccc}
\hline & \multicolumn{3}{c}{$\boldsymbol{t r} \mathbf{1} \mathbf{~ s}$} & \multicolumn{3}{c}{$\boldsymbol{t r}=\mathbf{1 . 5} \mathbf{~ s}$} & \multicolumn{3}{c}{$\boldsymbol{t r}=\mathbf{2} \mathbf{~ s}$} \\
\cline { 2 - 10 } $\begin{array}{c}\text { Clearance Time } \\
(\mathrm{s})\end{array}$ & $X_{s}(\mathrm{~m})$ & $X_{0}(\mathrm{~m})$ & $D Z(\mathrm{~m})$ & $X_{s}(\mathrm{~m})$ & $X_{0}(\mathrm{~m})$ & $D Z(\mathrm{~m})$ & $X_{s}(\mathrm{~m})$ & $X_{0}(\mathrm{~m})$ & $\begin{array}{c}D Z \\
(\mathrm{~m})\end{array}$ \\
\hline 3 & 129.19 & 40.01 & 89.18 & 141.69 & 40.01 & 101.68 & 154.19 & 40.01 & 114.18 \\
4 & 129.19 & 65.01 & 64.18 & 141.69 & 65.01 & 76.68 & 154.19 & 65.01 & 89.18 \\
5 & 129.19 & 90.01 & 39.18 & 141.69 & 90.01 & 51.68 & 154.19 & 90.01 & 64.18 \\
6 & 129.19 & 115.01 & 14.17 & 141.69 & 115.01 & 26.67 & 154.19 & 115.01 & 39.18 \\
\hline
\end{tabular}




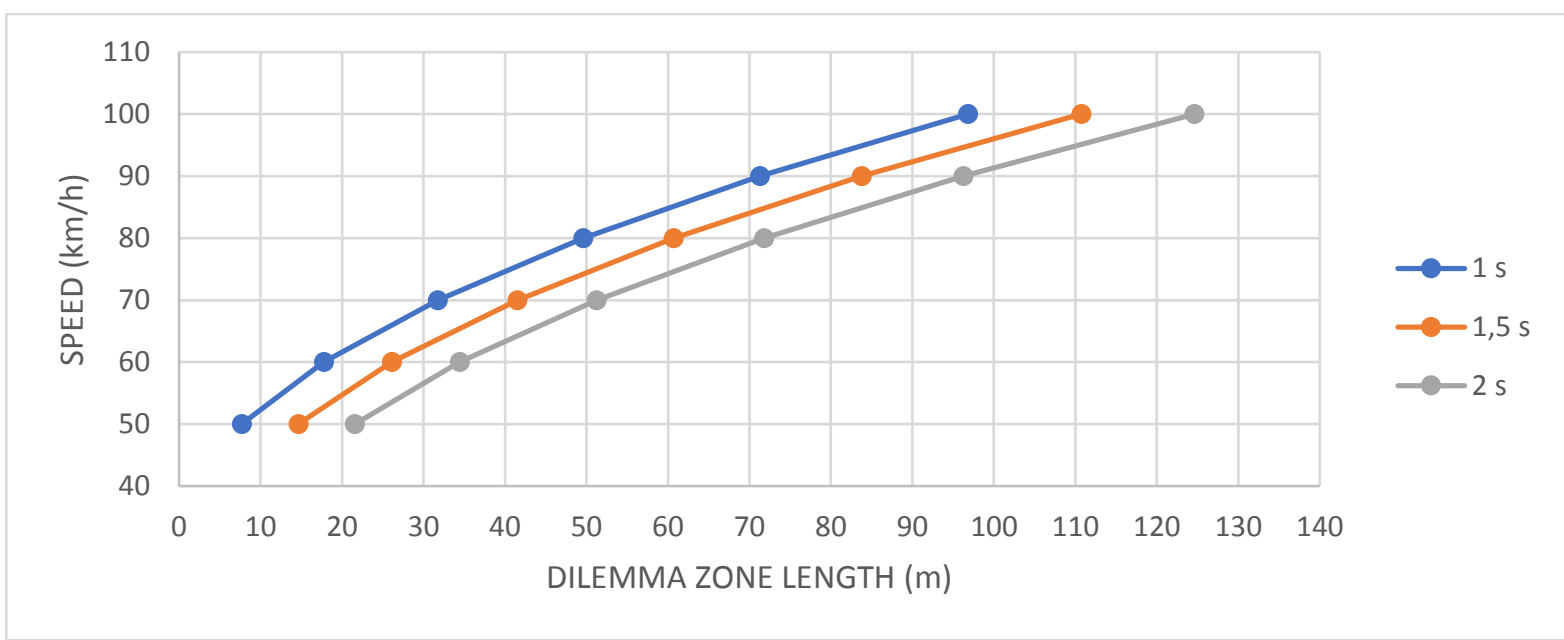

Fig. 5. The relation between speed, perception-reaction time and the dilemma zone

$$
\left(t_{c}=5 \mathrm{~s}, a=2 \mathrm{~m} / \mathrm{s}^{2}, W=15 \mathrm{~m}\right)
$$

Tables 6 and 7 illustrate the relationship between clearance time and perception-reaction time in the determination of the dilemma zone. As seen from the Tables, the Type I dilemma zone length decreases with an increase of clearance time. On the other hand, it also increases with the increase of the perception-reaction time. This is not surprising, since taken distance on the road is dependent not only on perception-reaction time but also on the speed of the vehicle. This is the reason the dilemma zone values in Table 7 are greater than those in Table 6 . In addition, Figure 5 graphically depicts the impact of perception-reaction time. A look at Table 6 shows that due to enlarging clearance time, the Type I dilemma zone turns into a decision zone (Type II dilemma zone). As mentioned before, while a longer clearance time eliminates the Type I dilemma zone, it causes a longer decision zone. This circumstance is coherent with other studies in the literature $[25,30]$.

\section{CONCLUSIONS}

When at a yellow light in a signalised intersection, a driver faces the uncertainty of whether to stop or go through the intersection. He or she decides this uncertainty. If his decision is incorrect, it results in a red-light violation or a collision at the intersection. Therefore, to reduce the dilemma zone problem and improve intersection safety, many efforts have been proceeded by not only traffic researchers but also decision-makers.

This study helps to better understand the dilemma zone issue, especially the Type I dilemma zone concept. At the same time, it investigates the relations among the factors affecting the dilemma zone length. To analyse the relationships, 648 different traffic cases were considered. The study results showed that increasing yellow time or clearance time eliminates the Type I dilemma zone but increases the uncertainty in the driver's decision, namely creating the Type II dilemma zone. Further, the study indicated that the Type I dilemma zone length increased with the increase of speed, perception-reaction time, the intersection width (plus the length of vehicle) but decreased with an increasing deceleration rate. For future dilemma zone studies, other factors, such as traffic signal countdown timers, the effect of adverse weather condition, gradient, advanced dilemma zone warning system, vehicle type, vehicle position in traffic flow, should also be investigated. 


\section{References}

1. AASHTO, 2011. A Policy on Geometric Design of Highways and Streets, 6 th edition. American Association of State Highway and Transportation Officials, Washington, D.C. ISBN: 978-1-56051-508-1.

2. Audu Akeem A., Olufemi F. Iyiola, Ayobami A. Popoola, Bamiji M. Adeleye, Samuel Medayese, Choene Mosima, Nunyi Blamah. 2021. „The application of geographic information system as an intelligent system towards emergency responses in road traffic accident in Ibadan". Journal of Transport and Supply Chain Management 15(a546): 1-17. ISSN: 2310-8789.

3. Bonneson James, Dan Middleton, Karl Zimmerman, Hassan Charara, Montasir Abbas, 2002. , Intelligent detection-control system for rural signalized intersections. Report No. FHWA /TX-02 /4022-2. Texas Department of Transportation, Austin. Texas.

4. Czech Piotr. 2017. „Underage pedestrian road users in terms of road accidents”. In: Advances in Intelligent Systems and Computing 505: 33-44. DOI: 10.1007/978-3-31943991-4_4. Edited by: Sierpinski G. Intelligent transport systems and travel behaviour. 13th Scientific and Technical Conference on Transport Systems. Theory and Practice (TSTP). Katowice, SEP 19-21, 2016.

5. Danilevičius Algimantas, Marijonas Bogdevičius, Modesta Gusarovienè, Gediminas Vaičiūnas, Robertas Pečeliūnas, Irena Danilevičienè. 2018. "Determination of Optimal Traffic Light Period Using a Discrete Traffic Flow Model". Mechanika 24(6): 845-851.

6. Drozdziel Pawel, Slawomir Tarkowski, Iwona Rybicka, Rafal Wrona, 2020. 'Drivers' reaction time research in the conditions in the real traffic" Open Engineering 10(1): 3547. DOI: https://doi.org/10.1515/eng-2020-0004.

7. El-Shawarby Ihab, Hesham Rakha, Vaughan Inman, Gregory Davis, 2007. "Evaluation of driver deceleration behavior at signalized intersections". Transportation Research Board 86th Annual Meeting. January 22-25, 2007. Washington D.C., U.S.A.

8. El-Shawarby Ihab, Ahmed Amer, Hesham Rakha, 2008. "Evaluation of driver stopping behavior on high-speed signalized intersection approaches", Transportation Research Board 87th Annual Meeting. January 13-17, 2008. Washington D.C., U.S.A.

9. Gazis Denos, Robert Herman, Alexei Maradudin. 1960. "The problem of the amber signal light in traffic flow". Operations Research 8(1): 112-132.

DOI: https://doi.org/10.1287/opre.8.1.112.

10. Green Marc. 2008. "How long does it take to stop? Methodological analysis of driver perception-brake times". Transportation Human Factors 2(3): 195-216.

DOI: https://doi.org/10.1207/STHF0203_1.

11. Hichim Majid Farag, Ahmed Shany Khusheef, Saddam Hasan Raheemah. 2020. "The Effects of Driver Age and Gender on Vehicle Stopping Distance Under Different Speeds". European Transport $\backslash$ Trasporti Europei 80(1): 1-11. ISSN 1825-3997. DOI: https://doi.org/10.48295/ET.2020.80.1.

12. ITE Technical Committee 18 (Chair: Parsonson Peter), 1974. "Small area detection at intersection approaches". Traffic Engineering 44(2): 8-17.

13. ITE.1999. Traffic Engineering Handbook. Prentice Hall Englewood Cliffs. ISBN: 0-935403-32-9.

14. Kell James H., Iris J. Fullerton. 1998. Manual of Traffic Signal Design. 3rd ed. Englewood Cliffs, NJ: Institute of Transportation Enginerering, Prentice-Hall. ISBN: 978-0135543382. 
15. Machiani Sahar Ghanipoor, Montasir Abbas. 2016. "Safety surrogate histogram (SSH): A novel real-time safety assessment of dilemma zone related conflicts at signalized intersections". Journal of Accident Analysis and Prevention 96: 361-370. DOI: https://doi.org/10.1016/j.aap.2015.04.024.

16. Magister Tone, Rok Krulec, Milan Batista, Leon Bogdanović. 2005. "The driver reaction time measurement experiences". In: Proceedings of the 7th Conference and Exhibition Innovative Automotive Technology IAT'05: 751-761. 21-22 April 2005. Bled, Slovenia.

17. Moon J. Young, Fred Coleman. 2003. "Dynamic dilemma zone based on driver behavior and car-following model at highway - rail intersections". Transportation Research Part B: Methodological 37(4): 323-344. DOI: https://doi.org/10.1016/S0191-2615(02)00014-0

18. MUTCD. 2009. The Manual on Uniform Traffic Control Devices (MUTCD) for Streets and Highways, 2009 Edition. US Department of Transportation the Federal Highway Administrator.

19. Papaioannou Panagiotis. 2007. "Driver behaviour dilemma zone and safety effects at urban signalised intersections in Greece". Accident Analysis \& Prevention 39(1): 147-158. DOI: https://doi.org/10.1016/j.aap.2006.06.014.

20. Pawar Digvijay, Dibyendu Pathak, Gopal Patil. 2020. „Modeling dynamic distribution of dilemma zone at signalized intersections for developing world traffic". Journal of Transportation Safety \& Security. DOI: 10.1080/19439962.2020.1852464.

21. Prentkovskis Olegas, Edgar Sokolovskij, Vilius Bartulis. 2010. "Investigating traffic accidents: a collision of two motor vehicles". Transport 25(2): 105-115.

22. Puan Othman Che, Che Ros Ismail. 2010. "Dilemma zone conflicts at isolated intersections controlled with fixed-time and vehicle actuated traffic signal systems". International Journal of Civil and Environmental Engineering 10(3): 19-25.

23. Rakha Hesham, Ihab El-Shawarby, Jose Reynaldo, Setti. 2007. "Characterizing driver behavior on signalized intersection approaches at the onset of a yellow-phase trigger". IEEE Transactions on Intelligent Transportation Systems 8(4): 630-640 DOI: 10.1109/TITS.2007.908146.

24. Rakha Hesham, Ahmed Amer, Ihab El-Shawarby. 2008. "Modeling driver behavior within a signalized intersection approach decision-dilemma zone". Transportation Research Record: Journal of the Transportation Research Board 2069(1): 16-25. DOI: https://doi.org/10.3141/2069-03.

25. Saito TN. Ooyarna, Kojiro Sigeta. 1990. "Dilemma and option zones, the problem and countermeasures-characteristics of zones, and a new strategy of signal control for minimizing zones". In: Proceedings of the Third International Conference on Road Traffic Control. London, UK. 1-3 May 1990. P. 137-141.

26. Setti Jose Reynaldo, Hesham Rakha, Ihab El-Shawarby. 2007. "Analysis of brake perception-reaction times on high-speed signalized intersection approaches". Transportation Research Board 86th Annual Meeting. January 22-25, 2007. Washington D.C., U.S.A.

27. Si Jianwen, Thomas Urbanik, Lee Han L. 2007. "Effectiveness of alternative detector configurations for option zone protection on high-speed approaches to traffic signal". Transportation Research Record 2035(1): 107-113.

DOI: https://doi.org/10.3141/2035-12.

28. Taoka George. 1989. "Break reaction times of unaltered drivers". ITE Journal 59(3): 19-21. 
29. Tarko Andrew, Wei Li, Luis Laracuente. 2006. "Probabilistic approach to controlling dilemma occurrence at signalized intersections". Transportation Research Record: Journal of the Transportation Research Board 1973(1): 55-63. DOI: https://doi.org/10.1177/0361198106197300107.

30. Urbanik Tom, Peter Coonce. 2007. "The dilemma with dilemma zones". ITE District $6^{\text {th }}$ Annual Meeting. Portland, Oregon.

31. Zegeer Charles. 1977. "Effectiveness of green-extension systems at high speed intersections" Research Report 472. Kentucky Department of Transportation, Lexington, Kentucky, USA.

32. Zegeer Charles, Robert Deen. 1978. "Green-extension systems at highspeed intersection". ITE Journal 48(11): 19-24.

33. Zhang Yaping, Chuanyun Fu, Liwei Hu. 2014. "Yellow light dilemma zone researches a review". Journal of Traffic and Transportation Engineering 1(5): 338-352.

DOI: https://doi.org/10.1016/S2095-7564(15)30280-4.

Received 02.04.2021; accepted in revised form 30.05.2021

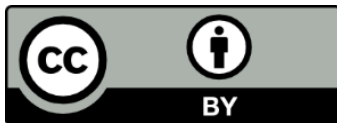

Scientific Journal of Silesian University of Technology. Series Transport is licensed under a Creative Commons Attribution 4.0 International License 